\title{
Performance Comparation of Real Time Image Processing Face Recognition for Security System
}

\author{
Tri Randi Uetama \\ Master of Mechanical Engineering \\ Swiss German University \\ Tangerang City, Indonesia \\ randi.gamaplantation@gmail.com
}

\author{
${ }^{*}$ Widi Setiawan \\ Master of Mechanical Engineering \\ Swiss German University \\ Tangerang City, Indonesia \\ widi_setia@yahoo.com
}

\author{
Edi Sofyan \\ Master of Mechanical Engineering \\ Swiss German University \\ Tangerang City, Indonesia \\ edisofyan@hotmail.com
}

\begin{abstract}
This research had been developed a system mainly consists of Arduino microcontoller based hardware and neural network based algorithms. The system has been fully assembled and successfully tested. By using two different methods the point feature detector (PFD) method was used as the first method. An Eigen Feature function was utilized to detect feature point of image. The second method is convolutional neural network (CNN) to recognize human face. Using PFD method, a classification value has been setup $<11$. The classification value is used as classification category of the program to recognize the subject (face image) correctly. By using PFD method, the response of the system from starting of a face image recognition until opening the locker is 20 second. The CNN method used alexnet to classify the image. At least around 300 training input data are use per person. The face recognition's experiment reached a high recognition's accuracy of $99.99 \%$ level and an average response time of 10 seconds. This research presents how the human face can be recognized and used to control the opening of a door lock.
\end{abstract}

Keywords - eigen feature, feature point detector, convolution neural network, alexnet, classification value.

\section{INTRODUCTION}

Visual is the most complicated of our sense [1]. Many of the researcher had studied and conduct lots of experiment in order to achieve the most sophisticated technology by utilize visual feedback. Visual feedback method allowed a device or a certain system to be able to controlled by using image processing and make a final decision of movement. A camera is a passive device to capture patterns from optical energy reflected from the scene. A single camera has a limitation in 3-dimensiooonal structures in scanning and lost in resulting in 2-dimentional image. Despite this problem, a human is particularly good to inferring in 3dimensional nature of scene. In Fig. 1 shows how the 2dimensional image can inferred as the 3-dimensional object

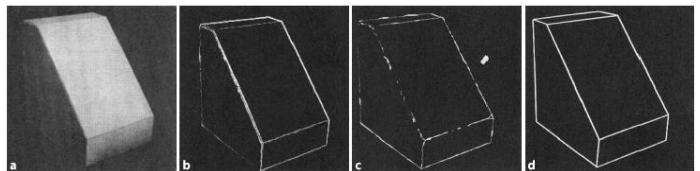

Fig. 1 (a) Original picture; (b) gradient image; (c) connected feature points; (d) reconstructed line drawing [1]
In image processing, MATLAB offers lot of tools that very effective in image signal processing. Image pattern analyses, convolution neural network (CNN), and deep learning is implementable. Additional MATLAB has a function in order to connect microcontroller and camera device.

In this research the image processing method has been implement to control a device by recognizing the human face. To be more applicable the experiment was used solenoid door locker as the actuator.

\section{THEORITICAL PERSPECTIVE}

\section{A. Image}

Image is two of dimension of discrete $\mathrm{I}(\mathrm{m}, \mathrm{n})$ that is output or response of some of sensor at a series of fix positions $(\mathrm{m}=1,2, \ldots, \mathrm{M}), \mathrm{n}=1,2 \ldots, \mathrm{N})$ in 2 -D cartesian coordinate. An image respectively designated the rows and columns. Image has individual elements or pixels revered by their index or coordinate. An image colour have intensity level or value to every single of pixel location $\mathrm{I}(\mathrm{m}, \mathrm{n})$.

The size of 2-D pixel stored for each of individual image pixel determine resolution and colour of image. From mathematical view any of 2-D array can be considered as image signal.

Such as measurement data and decision. Image digitization for example image sampling $x, y$ and gray level quantization. Image represent rectangular array integers. the image size and gray level are usually integer of power of 2. Number of each pixel represent the bright and darkness of the image.
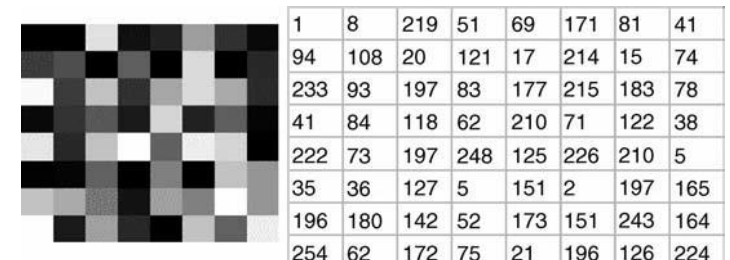

*Corresponding Author | Widi Setiawan | Email: widi_setia@yahoo.com

Tangerang - Indonesia, 28 September 2020 
Fig 2. Digital image and numerical representation [2] TABLE I

COMMON IMAGE FORM ATS AND PROPERTIES

\begin{tabular}{|c|c|c|}
\hline Acronym & Name & Properties \\
\hline GIF & $\begin{array}{c}\text { Graphics } \\
\text { interchange format }\end{array}$ & $\begin{array}{l}\text { Limited to only } 256 \text { colours ( } 8 \\
\text { bit); lossless compression }\end{array}$ \\
\hline JPEG & $\begin{array}{l}\text { Joint Photographic } \\
\text { Experts Group }\end{array}$ & $\begin{array}{l}\text { In most common use today; } \\
\text { lossy } \\
\text { compression; lossless variants } \\
\text { exist }\end{array}$ \\
\hline BMP & Bit map picture & $\begin{array}{c}\text { Basic image format; limited } \\
\text { (generally) lossless } \\
\text { compression; lossy variants } \\
\text { exist }\end{array}$ \\
\hline PNG & $\begin{array}{l}\text { Portable network } \\
\text { graphics }\end{array}$ & $\begin{array}{l}\text { New lossless compression } \\
\text { format; designed to replace GIF }\end{array}$ \\
\hline TIF/TIFF & $\begin{array}{l}\text { Tagged image } \\
\text { (file) format }\end{array}$ & $\begin{array}{c}\text { Highly flexible, detailed and } \\
\text { adaptable format; } \\
\text { compressed/uncompressed } \\
\text { variants exist }\end{array}$ \\
\hline
\end{tabular}

\section{B. Neural Network}

A neural network is very powerful and most common used in image processing. There are many kinds of neural network method was used to recognize an image. Basically neural network components have been inspired by McCulloch and Pitts' in 1943 by their paper "A logical calculus of ideas imminent in nervous activity". The same time Frank Rossenblatt was also developing the computation of human eye.

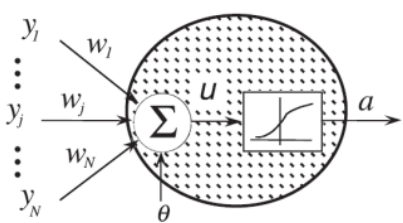

Fig 3. Neuron model of McCulloch and Pitts' [3]

$$
u=\sum_{j=1}^{N} w_{j} y_{j}+\theta
$$

TABLE II

SUMMARY OF NET FUNCTION

\begin{tabular}{ccc}
\hline Net function & Formula & Comments \\
\hline Linear & $u=\sum_{j=1}^{N} w_{j} y_{j}+\theta$ & $\begin{array}{c}\text { Most common } \\
\text { equation }\end{array}$ \\
$\begin{array}{c}\text { Higher order } \\
\text { (2nd order } \\
\text { formula } \\
\text { exhibited) }\end{array}$ & $u=\sum_{j=1}^{N} \sum_{K=1}^{N} w_{j k} y_{j} y_{k}+\theta$ & $\begin{array}{c}u_{i} \text { is weighted } \\
\text { linear } \\
\text { combination of } \\
\text { higher order } \\
\text { polynomial term } \\
\text { of input variable. } \\
\text { Where } N_{d} \text { is } \\
\text { input value and } \\
d \text { is the order of } \\
\text { polynomial. }\end{array}$ \\
Delta $(\Sigma-\Pi)$ & $u=\prod_{j=1}^{N} w_{j} y_{j}$ & $\begin{array}{c}\text { Seldom used } \\
\end{array}$ \\
\hline
\end{tabular}

$a_{i}$ is the input of the neuron is related with the input $u_{i}$ by linear or non linear or its called activation function.

TABLE III

SUMMARY OF ACTIVATION FUNCTION

\begin{tabular}{|c|c|c|}
\hline $\begin{array}{l}\text { Activation } \\
\text { function }\end{array}$ & Formula $a=f(u)$ & Derivatives $\frac{d f(u)}{d u}$ \\
\hline Sigmoid & $f(u)=\frac{1}{1+e^{-u / T}}$ & $f(u)=f(u)[1-f u] / T$ \\
\hline $\begin{array}{l}\text { Hyperbolic } \\
\text { tangent }\end{array}$ & $f(u)=\tanh \left(\frac{u}{T}\right)$ & $\left(1-[f(u)]^{2}\right) / T$ \\
\hline Inverse tangent & $f(u)=\frac{2}{\pi} \tan ^{-1}\left(\frac{u}{T}\right)$ & $\frac{2}{\pi T}-\frac{1}{1+(T)^{2}}$ \\
\hline Threshold & $f(u)= \begin{cases}1 & u>0 \\
-1 & u<0\end{cases}$ & $\begin{array}{l}\pi T \quad 1+(u / T)^{2} \\
-2(u-m) \cdot f(u) \\
/ \sigma^{2}\end{array}$ \\
\hline $\begin{array}{c}\text { Gaussian radial } \\
\text { basis }\end{array}$ & $f(u)=\exp \left[-\|u-m\|^{2} / \sigma^{2}\right]$ & $-2(u-m) \cdot f(u)$ \\
\hline Linear & $f(u)=a u+b$ & $a$ \\
\hline
\end{tabular}

\section{Convolution Neural Network}

Basically image recognition is classification. Recognizing the image whether recognizing the image of animal or human is the same as classifying. Before $\mathrm{CNN}$ the feature extractor has been designed. Therefore it required significant amount of cost. CNN yields the better image classifying. When feature point extractor is deeper. CNN consist a neural network to extract the image and another $\mathrm{CNN}$ can classifies feature of the image.

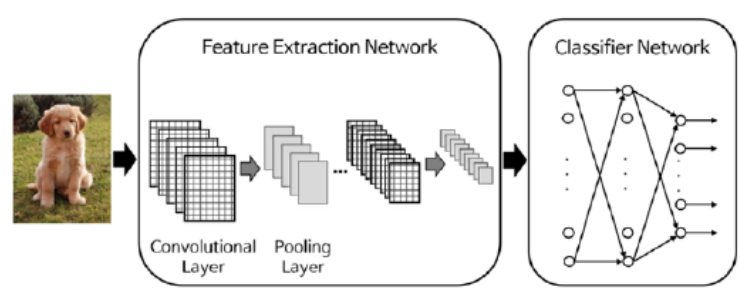

Fig 4. Typical architecture of CNN [4]

The input image enters into extraction network. After extracted the feature signal enter the classification neural network. Then the classification of CNN operates base on the feature of the image and generate the output.

\section{PREVIOUS STUDIES}

Image recognition research have been investigated in many of studies. A study about face recognition base on color vector binary pattern from multichannel face images has been investigated [5]. The study proposes the novel face descriptor based on color in formation. The study perform face recognition by local color vector binary pattern (LCVBPs) feature. The result show the LCBVTs is able to 
yield high performance in face recognition. Wang with study "Representing image base on point image" has been conducted [6]. The experiment utilize "verge points" to define the curvature image surface. Yeom [7] developed real time 3-d sensing the dynamic biological of microorganism. The study conducted to reconstruct the object by single-exposure on-line (SEOL) digital holography. The study is used pattern recognition by $3-d$ morphology and 3-d recognition. The result with sphacelaria alga, tribonema aequale alga, and polysiphonia alga are presented. Most research and study in image processing has been performed to recognize specific object for example bacteria, virus, human face, etc. A study to recognize tuberculosis bacteria [8] and vibrio cholera base on colors. Hui [9] with study "Research on face recognition algorithm based on improved convolution neural network". had been conducted. the experiment combine Fisher criterion to cover the poor property of $\mathrm{CNN}$. The result that combining the Fisher neural network (FNN) and convolution neural network can achieve good performance. In this study utilize Eigenfeature point detector and alexnet to recognize human face is investigated.

\section{RESEARCH METHODOLOGY}

\section{A. Material and Equipment}

In this research was used a webcam of computer as the sensor of the image, the input data will calculate by using Eigen Features function to detect point feature to recognize the image pattern. At the end calculating geometry changing of point or utilize alexnet tool in order to learning and classify the image. After that the signal from computer should sent to Arduino port to controlling the relay.

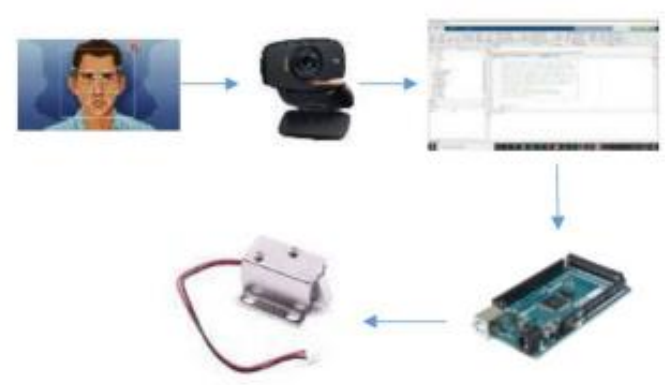

Fig 5. System flow process

The hardware circuit design is shows in Fig. 5 which is consisted kind of electronic devices. The solenoid door locker is required 12 Volt of input voltage, so voltage transformer is needed in order to obtain the voltage nominal value. Rectifier is attached to covert $\mathrm{AC}$ to $\mathrm{DC}$ and to get more stable voltage, a capacitor with 50 volt and $450 \mu \mathrm{F}$ was attached.

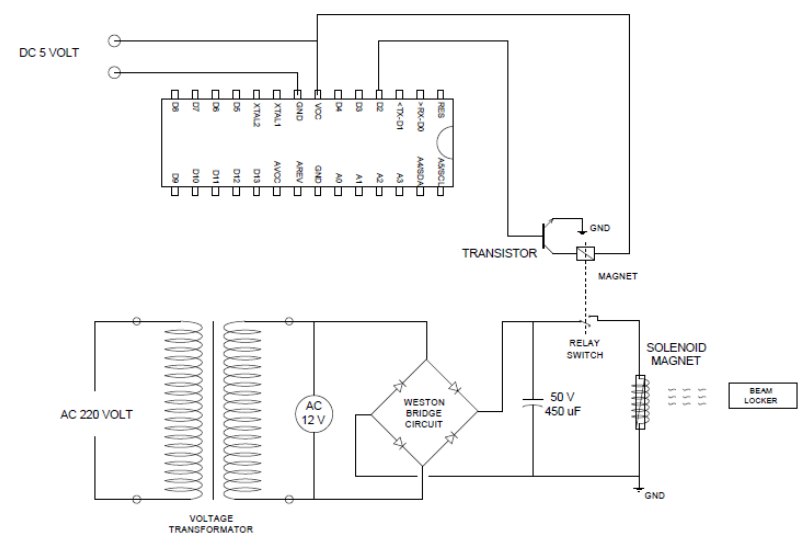

Fig 6. Circuit diagram

\section{B. Software Design}

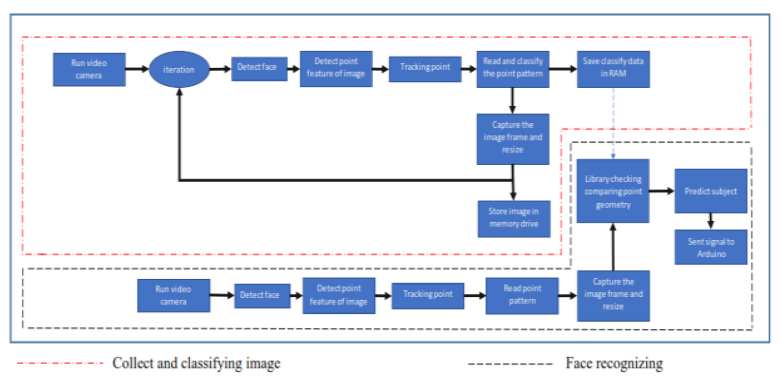

Fig 7. Face recognition base on PFD method block diagram

In the Fig. 7 depict the system work block diagram. The first software marked in dotted red line is to classifying and do looping iteration task to collect the images data. The images data is store into memory drive and classifying data is store in RAM (random access memory) of the computer. The second program is in dotted black line. This is part of recognizing the image from camera in real time. Identifying point feature is used to compare the point feature in the new image and old images. By calling the data classify from data base, the point feature analyzing the geometry point of both of the images in order to predict the subject [10].

\section{RESULT AND DISCUSSIONS}

A. Performance Test Face Recognition Of PFD Method

TABLE IV

OUTPUT CHANGING VS IMAGE RESOLUTION INPUT VALUE

\begin{tabular}{cccc}
\hline $\begin{array}{c}\text { Image } \\
\text { resolution } \\
\text { (pixel) }\end{array}$ & $\begin{array}{c}\text { Time } \\
\text { (second) }\end{array}$ & $\begin{array}{c}\text { Value of } \\
\text { variable } \\
\text { classification } \\
\text { Level of the } \\
\text { image }\end{array}$ & Output result \\
\hline $28 \times 23$ & 0 & - & Error \\
$56 \times 46$ & 0 & - & Error \\
$112 \times 92$ & 20 & 10 & Recognized \\
$224 \times 184$ & 0 & - & Error \\
\hline
\end{tabular}


TABLE V

Data ReCognizing Face With More Than One Person

\begin{tabular}{cccc}
\hline Subject & $\begin{array}{c}\text { Time } \\
\text { (second) }\end{array}$ & $\begin{array}{c}\text { Value of variable } \\
\text { classification } \\
\text { Level of the } \\
\text { image }\end{array}$ & Output result \\
\hline Randi & 20 & 10 & Recognized \\
Lia & 21 & 17 & Recognized \\
Tami & 20 & 27 & Recognized \\
\hline
\end{tabular}

TABLE VI

Subject ReCognition Experiment Result By Using Photo OR A

\begin{tabular}{ccccc}
\hline Subject & $\begin{array}{c}\text { Picture } \\
\text { attach on } \\
\text { front } \\
\text { camera }\end{array}$ & $\begin{array}{c}\text { Time } \\
\text { (second) }\end{array}$ & $\begin{array}{c}\text { Value of } \\
\text { variable } \\
\text { classification } \\
\text { Level of the } \\
\text { image }\end{array}$ & $\begin{array}{c}\text { Output } \\
\text { result }\end{array}$ \\
\hline Randi & Randi & 20.66 & 7 & Recognized \\
Randi & Wawan & 20.5 & - & $\begin{array}{c}\text { Un } \\
\text { identified } \\
\text { person } \\
\text { Un } \\
\text { Randi }\end{array}$ \\
& Tami & 19.89 & - & $\begin{array}{c}\text { identified } \\
\text { person }\end{array}$ \\
\hline
\end{tabular}

TABLE VII

TIME RESPONSE VS OUtPUT RESUlt WHEN ITERATION NUMBER OF

\begin{tabular}{ccccc}
\hline Subject & Loop & $\begin{array}{c}\text { Time } \\
\text { (second) }\end{array}$ & $\begin{array}{c}\text { Value of } \\
\text { variable } \\
\text { classification } \\
\text { Level of the } \\
\text { image }\end{array}$ & $\begin{array}{c}\text { Output } \\
\text { result }\end{array}$ \\
\hline Randi & 1 & 8.8 & 1 & Recognized \\
Randi & 5 & 9.07 & 2 & Recognized \\
Randi & 10 & 9.2 & 1 & Recognized \\
Randi & 15 & 9.44 & 2 & Recognized \\
Randi & 20 & 9.82 & 1 & Recognized \\
\hline
\end{tabular}

\section{B. Performance Test Of Convolution Neural Network} Method

TABLE VIII

OUTPUT CHANGING Vs IMAGE RESOLUTION INPUT VALUE

\begin{tabular}{ccccc}
\hline $\begin{array}{c}\text { Image } \\
\text { resolution } \\
\text { (pixel) }\end{array}$ & Layers & $\begin{array}{c}\text { Learning } \\
\text { time } \\
\text { until reach } \\
\mathbf{1 0 0 \%}\end{array}$ & $\begin{array}{c}\text { Recognition } \\
\text { time } \\
\text { (second) }\end{array}$ & $\begin{array}{c}\text { Output } \\
\text { result }\end{array}$ \\
\hline $100 \times 100$ & 25 & $5: 38.57$ & 10.05 & Recognized \\
$150 \times 150$ & 25 & $5: 8.62$ & 10.40 & Recognized \\
$200 \times 200$ & 25 & $6: 10.72$ & 12.76 & Recognized \\
$250 \times 250$ & 25 & $6: 21.32$ & 13.86 & Recognized \\
$300 \times 300$ & 25 & $6: 34.94$ & 15.55 & Recognized \\
$350 \times 350$ & 25 & $6: 40.56$ & 16.24 & Recognized
\end{tabular}


error in calculation. Geometry point transformation is can be used to recognize facial movement in order to increasing performance of the system. By adding the geometry transformation method the system can differentiate between living human or a picture and run the Arduino to switch the door locker.

The second method to recognize the face is using convolution neural network (CNN) has been investigated. By using alexnet tool an image can be predicted. In training part, the image must be contained a human face object to activate the face detector. The image captured and store in the memory or drive directly. Before run the training part the image resized in $227 \times 227$ pixel in order to make fit with alexnet's layer. The result of training saved in memory in variable newnet where the recognition part should call this variable when running. In recognition part the image capture from camera in real time. The image directly resize in $227 \times 227$ pixel to make it fit toward images that had been learned before. After that to run the prediction function to classify the image and compare the result toward the newnet data. The experiment result reach high accuracy at $99.99 \%$ level in training part and time response average at 10 seconds. This is how the system can recognize the human face. By this method is very robust and accurate because lots of data input can be set make the system can learn more. In the hardware part it found not much error when uploading and running the software but in this research is only used one pieces of Capacitor 50 Volt and $450 \mu \mathrm{F}$ in order to get DC voltage more stable. The instability of voltage led the solenoid of door locker shaking. To get it more stable, attach another smaller Capacitor 16 volt and 50 Volt and $450 \mu \mathrm{F}$ will be helpful. Adding another capacitor led the input DC voltage being purer.

\section{ACKNOWLEDGMENT}

This study is dedicated with wholeheartedly to my parents and all of my family who have been gave me motivation to achieve more acknowledge and gave me an inspiration and strength. I also thank to Dr. Ir. Widi Setiawan as my advisor who always support and give an advice regarding this thesis and also thank to Edi Sofyan, B.Eng., M.Eng., Ph.D, as my co-advisor who always give me an inspiration to solve many of my problem in this research.

\section{REFERENCES}

[1] K. S. Fu, ROBOTICS: Control, Sensing, Vision, and Intelligence, New York: McGraw-Hill, 1987.

[2] B. K. P. Hom, Robot Vision, MIT-Press, 1987.

[3] M. Ohka, H. Bin, and S. Che, "Object-handling tasks based on active tactile and slippage sensations," Robot Arms, 2011, doi: 10.5772/16781.

[4] P. Kim, MATLAB Deep Learning With Machine Learning, Neural Networks and Artificial Intelligence, Seoul: Apress, 2017.

[5] A. Kurniawan, Arduino Programming using MATLAB. PE Press, 2015.

[6] S. J. Wang, "Representing images using points on image surfaces," IEEE Transactions on Image Processing, 14 (8), pp. 1043 - 1056, 2005.

[7] S. Yeom, "Real-time 3-D sensing, visualization and recognition of dynamic biological icroorganisms," Proceedings of the IEEE, 94 (3), pp.550 - 566, April 2006.

[8] S. H. Lee, "Local color vector binary patterns from multichannel face images for face recognition', IEEE Transactions on Image Processing, 21 (4), pp. 2347 - 2353, 2012

[9] L. Hui and S. Yu-jie, "Research on face recognition algorithm based on improved convolution neural network," 2018 13th IEEE Conference on Industrial Electronics and Applications (ICIEA), Wuhan, 2018, pp. 2802-2805, doi: 10.1109/ICIEA.2018.8398186.

[10] B. Wibowo, E. Sofyan, G. Baskoro, "Prototype design of speed detection mobile application for golfers swing movement using computer vision compared to portable radar and accelerometer systems," $1^{\text {st }}$ Proceedings of The Conference on Management and Engineering in Industry (CMEI 2019)," vol. 1, pp. 49-52, Tangerang, Indonesia, August 2019. 